\title{
SARS-CoV-2 infection, male fertility and sperm cryopreservation: a position statement of the Italian Society of Andrology and Sexual Medicine (SIAMS) (Società Italiana di Andrologia e Medicina della Sessualità)
}

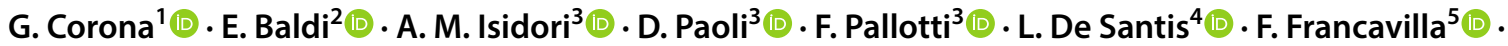

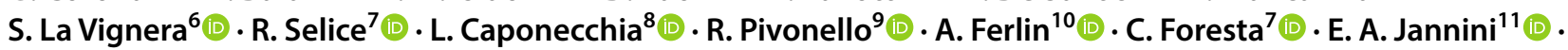 \\ A. Lenzi ${ }^{3}$ (D. Maggi ${ }^{12}$ (D) F. Lombardo ${ }^{3}$ (1)
}

Received: 24 April 2020 / Accepted: 2 May 2020 / Published online: 27 May 2020

(C) Italian Society of Endocrinology (SIE) 2020

\begin{abstract}
Purpose The recent pandemic of severe acute respiratory syndrome (SARS) due to coronavirus (CoV) 2 (SARS-CoV-2) has raised several concerns in reproductive medicine. The aim of this review is to summarize available evidence providing an official position statement of the Italian Society of Andrology and Sexual Medicine (SIAMS)

Methods A comprehensive Pubmed, Web of Science, Embase, Medline and Cochrane library search was performed. Due to the limited evidence and the lack of studies, it was not possible to formulate recommendations according to the Oxford 2011 Levels of Evidence criteria.

Results Several molecular characteristics of the SARS-CoV-2 can justify the presence of virus within the testis and possible alterations of spermatogenesis and endocrine function. Orchitis has been reported as a possible complication of SARS-CoV infection, but similar findings have not been reported for SARS-CoV-2. Alternatively, the orchitis could be the result of a vasculitis as COVID-19 has been associated with abnormalities in coagulation and the segmental vascularization of the testis could account for an orchitis-like syndrome. Finally, available data do not support the presence of SARS-CoV-2 in plasma seminal fluid of infected subjects.

Conclusion Data derived from other SARS-CoV infections suggest that in patients recovered from COVID-19, especially for those in reproductive age, andrological consultation and evaluation of gonadal function including semen analysis should be suggested. Studies in larger cohorts of currently infected subjects are warranted to confirm (or exclude) the presence of risks for male gametes that are destined either for cryopreservation in liquid nitrogen or for assisted reproduction techniques.
\end{abstract}

Keywords SARS-CoV-2 $\cdot$ COVID- $19 \cdot$ Semen cryopreservation $\cdot$ Male fertility

\section{Introduction}

Coronaviruses (CoV) are single-stranded RNA viruses, so named after the crown-like appearance given by glycoprotein spikes around the viral envelope, which can be observed by electron microscope. Coronaviridae family includes several genera (from $\alpha$ to $\delta$ ) that are capable to affect human and other vertebrates: the $\alpha-\mathrm{CoV}$ and $\beta-\mathrm{CoV}$ can affect human and various mammals by infecting respiratory,

G. Corona

jocorona@libero.it

Extended author information available on the last page of the article gastrointestinal, and central nervous system, while $\gamma$-CoV and $\delta$-CoV mainly affect birds $[1,2]$. Since the outbreak of severe acute respiratory syndrome (SARS)-CoV in the south of China in 2002, coronaviruses have been recognized as the cause of several epidemics throughout the world. Recently, a new viral strain appeared in the middle of the same country, in Wuhan [3], starting a pandemic that is currently involving over two million people around the world, more than 100,000 deaths and whose numbers are still increasing each day [4]. Italy is one of the most severely involved countries with up to 160,000 assessed cases and more than 20,000 deaths [5]. This new viral strain belongs to the $\beta-\mathrm{CoV}$ genus and has been named SARS-CoV-2. According to the current 
knowledge, the clinical manifestations of SARS-CoV-2 are commonly characterized by fever, cough, nasal congestion, asthenia, anosmia, ageusia and dyspnea. The infection may further evolve with the onset of systemic symptoms characterized by cardiovascular coagulation and liver impairment and an atypical pneumonia, that might require hospitalization [6]. The relatively high frequency of these life-threatening complications, together with the high transmissibility and swift global diffusion, forced serious responses from world authorities leading to severe restrictions in the attempt to control the pandemic of the coronavirus disease (COVID19) [7]. With the aim to contain the disease, researchers activated globally to clarify viral transmission routes and to validate diagnostic tests to quickly identify infected subjects. There is evidence of the SARS-CoV-2 RNA presence in various biological matrices such as stool samples, blood and urine: in stool in particular there seems to be a relatively high detection rate, with longer clearance time than nasopharyngeal swabs from respiratory secretions; blood and urine, instead, seem to have a very low frequency of viral RNA detection [8-10]. Nonetheless, this suggests that infection routes other than respiratory droplets are theoretically possible. The presence of SARS-CoV-2 in seminal fluid could have sexual and reproductive implications [11] and reflect in COVID-19 infection and transmission, but this matter has been under-investigated so far. Sperm cryopreservation is routinely used to preserve male fertility and to manage couple infertility in several clinical settings [12]. Cytotoxic agents used in cancer or some surgical intervention can impair spermatogenesis and alter ejaculation. In addition, surgical sperm extraction in azoospermic patients represents another specific indication for sperm freezing [13]. While conventional or microsurgical sperm extraction in patients with obstructive or non-obstructive azoospermia can be easily delayed because of the pandemic, semen cryopreservation cannot be delayed in cancer patients who need to start chemotherapy. In the latter situation, sperm cryobanks represent the only chance of patient's fertility preservation.

Based on the aforementioned considerations, the possibility that SARS-CoV-2 can be identified in seminal fluid has important implications in reproductive medicine, especially regarding medically assisted reproduction and gamete cryopreservation, where there is a wide margin of uncertainty $[14,15]$. The aim of the present paper is to summarize available evidence providing an official position statement of the Italian Society of Andrology and Sexual Medicine (SIAMS).

\section{Methods}

A comprehensive Pubmed, Web of Science, Embase, Medline and Cochrane library search was conducted based on the following keywords: ("testis"[MeSH Terms] OR "testis"[All
Fields]) AND ("sars virus"[MeSH Terms] OR ("sars"[All Fields] AND "virus"[All Fields]) OR "sars virus"[All Fields] OR ("sars"[All Fields] AND "cov"[All Fields]) OR "sarscov"[All Fields]).

Due to the limited level of evidence and a lack of good study quality and design, producing recommendations according to the Oxford 2011 Levels of Evidence criteria was not possible. However, specific statements summarizing the SIAMS position based on discussion on the available data amongst a board of experts of the field were provided.

\section{SARS-CoV-2 pathogenetic mechanisms of infection: the basis for testis localization}

As previously reported, SARS-CoV- 2 is a novel $\beta$-coronavirus sharing $80 \%$ sequence homology with the earlier SARS-CoV virus causing the SARS outbreak in 2003 [16]. However, SARS-CoV-2 presents distinct characteristics. Its 3D structure shows a more compact configuration, which increases its binding affinity for angiotensin converting enzyme 2 (ACE2) that serves as a viral receptor [17]. In addition, SARS-Cov-2 presents a polybasic (furin) cleavage site increasing the virus' ability to internalize into cells. All these features can explain, at least partially, the strongest clinical impact when compared to the other coronavirus [17].

ACE2 is highly expressed in a wide range of human tissues including testis [18]. In particular, within the testis ACE2 expression has been documented on seminiferous ducts cells, as well as on spermatogonia, Leydig and Sertoli cells confirming the potential risks associated with SARS-CoV-2 infection in the reproductive system [18]. In addition, furin domains are expressed in the epididymis of various domestic mammals including humans, further supporting the risk of genitalia localization of SARS-CoV-2 [19]. If SARS-CoV-2 uses the SARS-CoV receptor ACE2 for cell entry, the transmembrane protease, serine 2 (TMPRSS2) for $\mathrm{S}$ protein is priming such internalization resulting in an enhanced isolation of SARSCoV-2 in cells expressing this type II transmembrane serine protease [20]. TMPRSS2 is highly expressed in the prostate epithelial cells, including the apical plasma membrane of the prostate luminal cells. Its expression is regulated by androgens (apparently an androgen responsive elements is the only known promoter enhancer of this gene) and is also released into semen as a component of prostasomes, organelle-like vesicles that may facilitate sperm function and enhance male reproduction [21].

\section{SARS-CoV-2 and male fertility}

S-1 orchitis has been reported as a possible complication of SARS-CoV infection. Similar findings have not been reported for SARS-CoV-2. 
S-2 testicular function including testosterone and sperm concentrations should be monitored in patients recovered from with SARS-CoV-2.

S-3 available data do not support the presence of SARS$\mathrm{CoV}-2$ in seminal fluid of infected subjects.

\section{Evidence}

As previously reported, the presence of ACE2 in adult Leydig cells in the testis was proven long ago, with a putative steroidogenesis regulatory role [22], but its precise function, as well as the role for the entire renin-angiotensin system in testicular function regulation, has been investigated with respect to gender differences but not yet fully elucidated [23]. It is possible that viral binding to this metalloprotease might compromise testicular function and the consequent inflammation might lead to epididymo-orchitis with long lasting testicular damage and spermatogenesis impairment. While such occurrence has not yet been described for SARS-CoV-2, it was instead reported for a similar coronavirus SARS-CoV [24]. Alternatively, the orchitis could be the result of a vasculitis as COVID-19 has been associated with abnormalities in coagulation and the segmental vascularization of the testis could account for an orchitis-like syndrome. These observations indicate that it is imperative to monitor recovered COVID-19 men reproductive functions for any abnormalities that might impair future fertility. Accordingly, limited evidence documented that when compared to age-matched healthy men with normal fertility, COVID-19 patients showed a significant increase in serum LH level and a dramatic decrease in serum testosterone (T) to luteinizing hormone ( $\mathrm{LH})$ ratio, supporting the presence of a subclinical or compensated hypogonadism [25]. The latter is supported by the epidemiological observation of a higher incidence of complications in older diabetic men that have hypogonadism [26]. Finally, a rise in LH levels is known to increase testicular vascularization [27]. Another hot topic would be the safety and potential consequences of utilization of reproductive cells from SARS-CoV-2 positive subjects: the lack of knowledge currently prevents us from performing a thorough and exhaustive risk analysis regarding possible adverse events in the short or long term. The possible presence of SARS-CoV-2 has not yet been reported and there are only a few case reports investigating this issue. Recently, Paoli et al. [28] reported the absence of viral RNA in the semen fluid of a man with history of COVID-19. This was also confirmed by Pan et al. [29] in a small cohort of Chinese subjects. The latest research letter from $\mathrm{Li}$ et al. [30] drew attention for reporting 6 cases of positive SARS-CoV-2 semen samples in severe COVID-19 cases (about 16\% of the tested subjects). However, several concerns were raised for methodological issues [31].

\section{Remarks and further perspective}

It is important to recognize that all available data on the specific effects of SARS-CoV-2 on testicular function are derived from clinical cases or case series, which represent a major limitation for the data analysis. Hence further studies are required to draw final conclusions. However, data derived from other SARS-CoV infections suggest that in patients recovered from COVID-19, especially for those in reproductive age, andrological and sexological consultation and gonadal function evaluation including semen examination should be suggested [11]. In addition, it should be stressed that the results derived from the studies from Paoli et al., Pan et al. and Li et al. [28-30] can allow to speculate that SARS-CoV-2 clearance in seminal fluid overlaps with the clinical recovery or that the virus has never been present in the seminal fluid of the subject. The evaluation of the presence of SARS-CoV-2 in seminal samples is particularly important for semen cryopreservation, because viruses stored in liquid nitrogen retain their pathogenic properties [32]. For this reason, studies in larger cohorts of currently infected subjects are warranted to confirm (or exclude) the presence of risks for male gametes that are destined either for cryopreservation in liquid nitrogen or for assisted reproduction techniques.

Funding No funding was used to produce this manuscript.

\section{Compliance with ethical standards}

Conflict of interest On behalf of all authors, the corresponding author states that there is no conflict of interest.

Ethical approval This article does not contain any studies with human participants or animals performed by any of the authors.

Informed consent No informed consent is necessary for the study.

\section{References}

1. Ashour HM, Elkhatib WF, Rahman MM, Elshabrawy HA (2020) Insights into the recent 2019 novel coronavirus (SARS-CoV-2) in light of past human coronavirus outbreaks. Pathog (Basel, Switzerland). 9(3):186. https://doi.org/10.3390/pathogens9030186

2. Peng X, Xu X, Li Y, Cheng L, Zhou X, Ren B (2020) Transmission routes of 2019-nCoV and controls in dental practice. Int J Oral Sci 12:9

3. Cascella M, Rajnik M, Cuomo A, Dulebohn SC, Di Napoli R (2020) Features, evaluation and treatment coronavirus (COVID19). https://www.ncbi.nlm.nih.gov/books/NBK554776/

4. CSSE at Johns Hopkins University (2020) Coronavirus resource center. https://coronavirus.jhu.edu/map.html. Last Accessed $15 / 04 / 2020$ 
5. Italian Ministry of Health (2020) Covid-19, situation report update at 13 April 2020. https://www.salute.gov.it/portale/news/ p3_2_1_1_1.jsp?lingua $=$ italiano $\&$ menu $=$ notizie $\& \mathrm{p}=$ dalministe ro\&id=4228. Last Accessed 15/04/2020

6. Velavan TP, Meyer CG (2020) The COVID-19 epidemic. Trop Med Int Health 25:278-280

7. Corman VM, Landt O, Kaiser M et al (2020) Detection of 2019 novel coronavirus $(2019-\mathrm{nCoV})$ by real-time RT-PCR. Euro Surveill 25(3):2000045. https://doi.org/10.2807/1560-7917. ES.2020.25.3.2000045

8. Zheng S, Fan J, Yu F et al (2020) Viral load dynamics and disease severity in patients infected with SARS-CoV-2 in Zhejiang Province, China, January-March 2020: retrospective cohort study. BMJ 369:m1443. https://doi.org/10.1136/bmj.m1443

9. Ling Y, Xu S-B, Lin Y-X et al (2020) Persistence and clearance of viral RNA in 2019 novel coronavirus disease rehabilitation patients. Chin Med J (Engl). https://doi.org/10.1097/CM9.00000 00000000774

10. Xie C, Jiang L, Huang $\mathrm{G}$ et al (2020) Comparison of different samples for 2019 novel coronavirus detection by nucleic acid amplification tests. Int J Infect Dis 93:264-267

11. Aversa A, Jannini EA (2020) COVID-19, or the triumph of monogamy? Minerva Endocrinol. https://doi.org/10.23736/S0391 $-1977.20 .03207-1$

12. Hezavehei M, Sharafi M, Kouchesfahani HM, Henkel R, Agarwal A, Esmaeili V, Shahverdi A (2018) Sperm cryopreservation: a review on current molecular cryobiology and advanced approaches. Reprod Biomed Online 37:327-339

13. Corona G, Minhas S, Giwercman A, Bettocchi C, Dinkelman-Smit M, Dohle G, Fusco F, Kadioglou A, Kliesch S, Kopa Z, Krausz C, Pelliccione F, Pizzocaro A, Rassweiler J, Verze P, Vignozzi L, Weidner W, Maggi M, Sofikitis N (2019) Sperm recovery and ICSI outcomes in men with non-obstructive azoospermia: a systematic review and meta-analysis. Hum Reprod Update 25:733-757

14. ESHRE guidance on recommencing ART treatments (2020) ESHRE website, 23/04/2020. https://www.eshre.eu/Home/COVID 19WG

15. De Santis L, Anastasi A, Cimadomo D, Klinger FG, Licata E, Pisaturo V, Sosa Fernandez L, Scarica C (2020) COVID-19: the perspective of Italian embryologists managing the IVF laboratory in pandemic emergency. Hum Reprod (Oxford, England) 35(4):1004-1005. https://doi.org/10.1093/humrep/deaa074

16. Zhu N, Zhang D, Wang W, Li X, Yang B, Song J, Zhao X, Huang B, Shi W, Lu R, Niu P, Zhan F, Ma X, Wang D, Xu W, Wu G, Gao GF, Tan W, China Novel Coronavirus Iinvestigating and Research Team. (2019) A Novel Coronavirus from Patients with Pneumonia in China. N Engl J Med. 2020;382:727-733

17. Shang J, Ye G, Shi K, Wan Y, Luo C, Aihara H, Geng Q, Auerbach A, Li F (2020) Structural basis of receptor recognition by SARS-CoV-2. Nature. https://doi.org/10.1038/s41586-020-2179-y

18. Wang Z, Xu X (2020) scRNA-seq Profiling of human testes reveals the presence of the ACE2 receptor, a target for SARSCoV-2 infection in spermatogonia, leydig and sertoli cells. Cells 9(4):E920. https://doi.org/10.3390/cells9040920

19. Thimon V, Belghazi M, Dacheux JL, Gatti JL (2006) Analysis of furin ectodomain shedding in epididymal fluid of mammals: demonstration that shedding of furin occurs in vivo. Reproduction 132(6):899-908

20. Hoffmann M, Kleine-Weber H, Schroeder S, Krüger N, Herrler T, Erichsen S, Schiergens TS, Herrler G, Wu NH, NitscheA MMA,
Drosten C, Pöhlmann S (2020) SARS-CoV-2 cell entry depends on ACE2 and TMPRSS2 and is blocked by a clinically proven protease inhibitor. Cell 181:271-280.e8

21. Chen YW, Lee MS, Lucht A, Chou FP, Huang W, Havighurst TC, Kim K, Wang JK, Antalis TM, Johnson MD, Lin CY (2010) TMPRSS2, a serine protease expressed in the prostate on the apical surface of luminal epithelial cells and released into semen in prostasomes, is misregulated in prostate cancer cells. Am J Pathol 176(6):2986-2996. https://doi.org/10.2353/ajpath.2010.090665

22. Douglas GC, O'Bryan MK, Hedger MP, Lee DKL, Yarski MA, Smith AI, Lew RA (2004) The novel angiotensin-converting enzyme (ACE) homolog, ACE2, is selectively expressed by adult Leydig cells of the testis. Endocrinology 145:4703-4711

23. La Vignera S, Cannarella R, Condorelli RA, Torre F, Aversa A, Calogero AE (2020) Sex-Specific SARS-CoV-2 mortality: among hormone-modulated ACE2 expression, risk of venous thromboembolism and hypovitaminosis D. Int J Mol Sci 21(8):E2948. https://doi.org/10.3390/ijms21082948

24. Xu J, Qi L, Chi X, Yang J, Wei X, Gong E, Peh S, Gu J (2006) Orchitis: a complication of severe acute respiratory syndrome (SARS). Biol Reprod 74:410-416

25. Pozzilli P, Lenzi A (2020) Testosterone, a key hormone in the context of COVID-19 pandemic. Metabolism (in press). https:// doi.org/10.1016/j.metabol.2020.154252

26. Corona G, Isidori AM, Aversa A, Bonomi M, Ferlin A, Foresta C, La Vignera S, Maggi M, Pivonello R, Vignozzi L, Lombardo F (2020) Male and female sexual dysfunction in diabetic subjects: focus on new antihyperglycemic drugs. Rev Endocr Metab Disord 21:57-65. https://doi.org/10.1007/s11154-019-09535-7

27. Manganaro L, Saldari M, Pozza C, Vinci V, Gianfrilli D, Greco E, Franco G, Sergi ME, Scialpi M, Catalano C, Isidori AM (2018) Dynamic contrast-enhanced and diffusion-weighted MR imaging in the characterisation of small, non-palpable solid testicular tumours. Eur Radiol 28:554-564. https://doi.org/10.1007/s0033 0-017-5013-7

28. Paoli D, Pallotti F, Colangelo S, Basilico F, Mazzuti L, Turriziani O, Antonelli G, Lenzi A, Lombardo F (2020) Study of SARS-CoV-2 in semen and urine samples of a volunteer with positive rino-pharyngeal swab. J Endocrinol Invest. https://doi. org/10.1007/s40618-020-01261-1

29. Pan F, Xiao X, Guo J, Song Y, Li H, Patel DP, Spivak AM, Alukal JP, Zhang X, Xiong C, Li PS, Hotaling J (2020) No evidence of SARS-CoV-2 in semen of males recovering from COVID-19. Fertil Steril. https://doi.org/10.1016/j.fertnstert.2020.04.024 (in press)

30. Li D, Jin M, Bao P, Zhao W, Zhang S (2020) Clinical characteristics and results of semen tests among men with coronavirus disease 2019. JAMA Netw Open 3(5):e208292

31. Paoli D, Pallotti F, Turriziani O, Mazzuti L, Antonelli G, Lenzi A, Lombardo F (2020) SARS-CoV-2 presence in seminal fluid: myth or reality. Andrology. https://doi.org/10.1111/ANDR.12825 (in press)

32. De Paoli P (2005) Bio-banking in microbiology: from sample collection to epidemiology, diagnosis and research. FEMS Microbiol Rev 29(5):897-910

Publisher's Note Springer Nature remains neutral with regard to jurisdictional claims in published maps and institutional affiliations. 


\section{Affiliations}

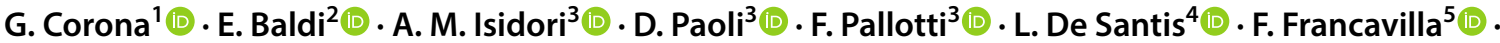

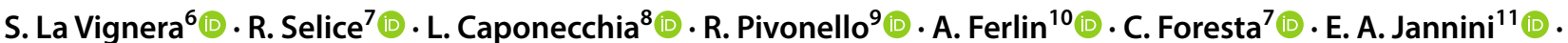

\section{A. Lenzi ${ }^{3}$ (D) M. Maggi ${ }^{12}$ (D) F. Lombardo ${ }^{3}$ (1)}

E. Baldi

elisabetta.baldi@unifi.it

A. M. Isidori

andrea.isidori@uniroma1.it

D. Paoli

donatella.paoli@uniroma1.it

F. Pallotti

francesco.pallotti@uniroma1.it

L. De Santis

desantis.lucia@hsr.it

F. Francavilla

felice.francavilla@univaq.it

S. La Vignera

sandrolavignera@unict.it

R. Selice

rselice@hotmail.com

L. Caponecchia

luisa.caponecchia@gmail.com

R. Pivonello

rosario.pivonello@unina.it

A. Ferlin

alberto.ferlin@unibs.it

C. Foresta

carlo.foresta@unipd.it

E. A. Jannini

eajannini@gmail.com

A. Lenzi

andrea.lenzi@uniroma1.it

M. Maggi

mario.maggi@unifi.it

F. Lombardo

francesco.lombardo@uniroma1.it
1 Endocrinology Unit, Medical Department, MaggioreBellaria Hospital, Largo Nigrisoli 2, 40133 Bologna, Italy

2 Department of Experimental and Clinical Medicine, University of Florence, Florence, Italy

3 Department of Experimental Medicine, "Sapienza" University of Rome, Rome, Italy

4 IVF Unit, Gynaecological-Obstetric Department, San Raffaele Scientific Institute, Vita-Salute University, Milan, Italy

5 Andrology Unit, Department of Clinical Medicine, Public Health, Life and Environment Sciences, University of L'Aquila, L'Aquila, Italy

6 Department of Clinical and Experimental Medicine, University of Catania, Catania, Italy

7 Department of Medicine, Unit of Andrology and Reproductive Medicine, University of Padova, Padova, Italy

8 Andrology and Pathophysiology of Reproduction Unit, Santa Maria Goretti Hospital, Latina, Italy

9 Dipartimento di Medicina Clinica e Chirurgia, Sezione di Endocrinologia, Unità di Andrologia e Medicina della Riproduzione e della Sessualità Maschile e Femminile (FERTISEXCARES), Università Federico II di Napoli; Staff of Unesco Chair for Health Education and Sustainable Development, Federico II University, Naples, Italy

10 Department of Clinical and Experimental Sciences, Unit of Endocrinology and Metabolism, University of Brescia, Brescia, Italy

11 Chair of Endocrinology and Medical Sexology (ENDOSEX), Department of Systems Medicine, University of Rome Tor Vergata, Roma, Italy

12 Endocrinology Unit, Department of Experimental Clinical and Biomedical Sciences "Mario Serio", University of Florence, Florence, Italy 